\title{
Horizontal ridge augmentation using GBR with a native collagen membrane and 1:1 ratio of particulated xenograft and autologous bone: a 3-year prospective clinical study
}

\author{
Meloni SM, Tallarico M, Canullo L, Pisano M, Jovanovic SA. \\ University of Sassari, Italy \\ Pre-op picture
}

\begin{abstract}
Aim
to clinically and radiographically evaluate bone regeneration of severe horizontal bone defects.
\end{abstract}

\section{Material and Methods}

This study was designed as a single cohort, prospective clinical trial. Partially or fully edentulous patients, having less then $4 \mathrm{~mm}$ of residual horizontal bone width were selected and consecutively treated with resorbable collagen membranes and a 1:1 mixture of particulated anorganic bovine bone and autogenous bone, 7 months before implant placement. Tapered body implants were inserted and loaded 3 to 6 months later with a screw retained crown or bridge. Outcomes were: implant survival rate, any biological and prosthetic complications, horizontal alveolar bone dimensional changes measured on cone beam computed tomography (CBCT) taken at baseline and at implant insertion, peri-implant marginal bone level changes measured on periapical radiographs, plaque index $(\mathrm{PI})$, and bleeding on probing index $(\mathrm{BoP})$.
\end{abstract}

\section{Results}

Eighteen consecutive patients ( 11 females, 7 males) with a mean age of 56.8 years (range 24-78) and 22 treated sites received 55 regular platform implants. No patient dropped-out and no implants failed during the entire follow-up, resulting in a cumulative implant survival rate of $100 \%$. No prosthetic or biological complications were recorded. Supraimposition of pre- and 7-month postoperative CBCT scans revealed an average horizontal bone gain of of $5.03 \pm 2.15 \mathrm{~mm}(95 \% \mathrm{Cl}: 4.13-5.92 \mathrm{~mm})$. Three year after implant installation, mean marginal bone loss was $1.15 \pm 0.28 \mathrm{~mm}(95 \% \mathrm{Cl} 0.84-1.22 \mathrm{~mm})$. PI was $11.6 \%$ and BoP was $5.2 \%$.

\section{Conclusions}

Within the limitation of the present study, high implant survival rate and high average bone augmentation seem to validate the use of collagen resorbable membranes with a 1:1 mixture of particulated anorganic bovine bone and autogenous bone, for the reconstruction of severe horizontal ridge defects.

Buser D, Ingimarsson S, Dula K, Lussi A, Hirt HP, Belser UC. Long-term stability of osseointegrated implants in augment- ed bone: A 5 -year prospective study in partially edentulous patients. Int J Periodontics Restorative Dent 2002; 22:109-117.

Chiapasco M, Casentini P, Zaniboni M, Corsi E. Evaluation of peri-implant bone resorption around Straumann Bone Level implants placed in areas reconstructed with autogenous vertical onlay bone grafts.

Urban IA, Jovanovic S, Lozada JL Vertical ridge augmentation using guided bone regeneration (GBR) in Tree clinical scenarios prior to implat placent: A rettospctive staly of 35 patients 12 to 72 moths

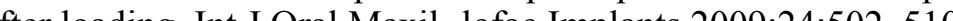

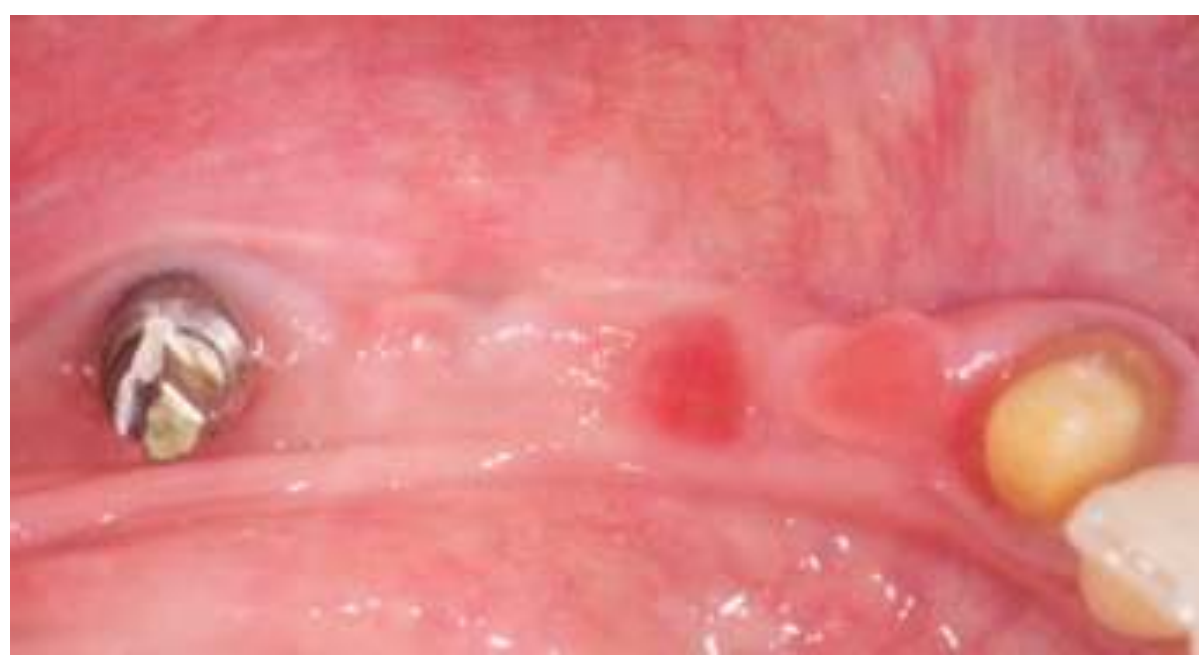

Horizontal GBR with 50\% autologous bone $50 \%$ anorganic bovine bone and collagen membrane

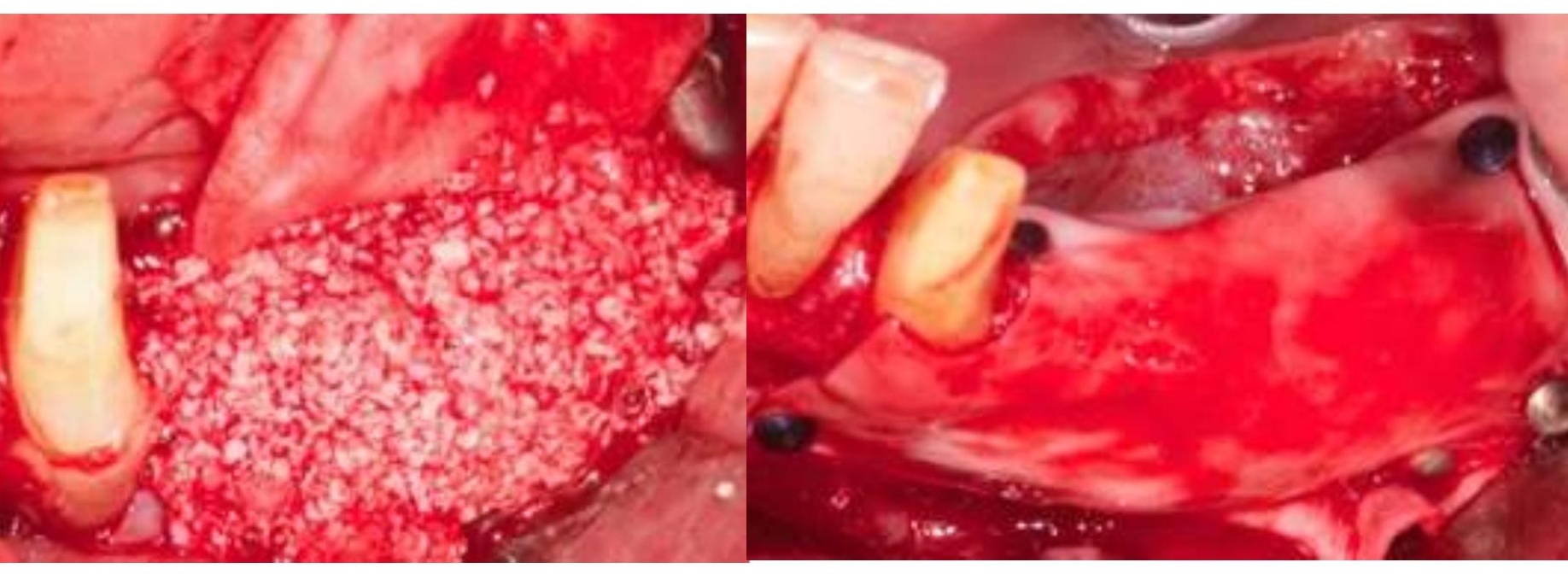

Implant installation

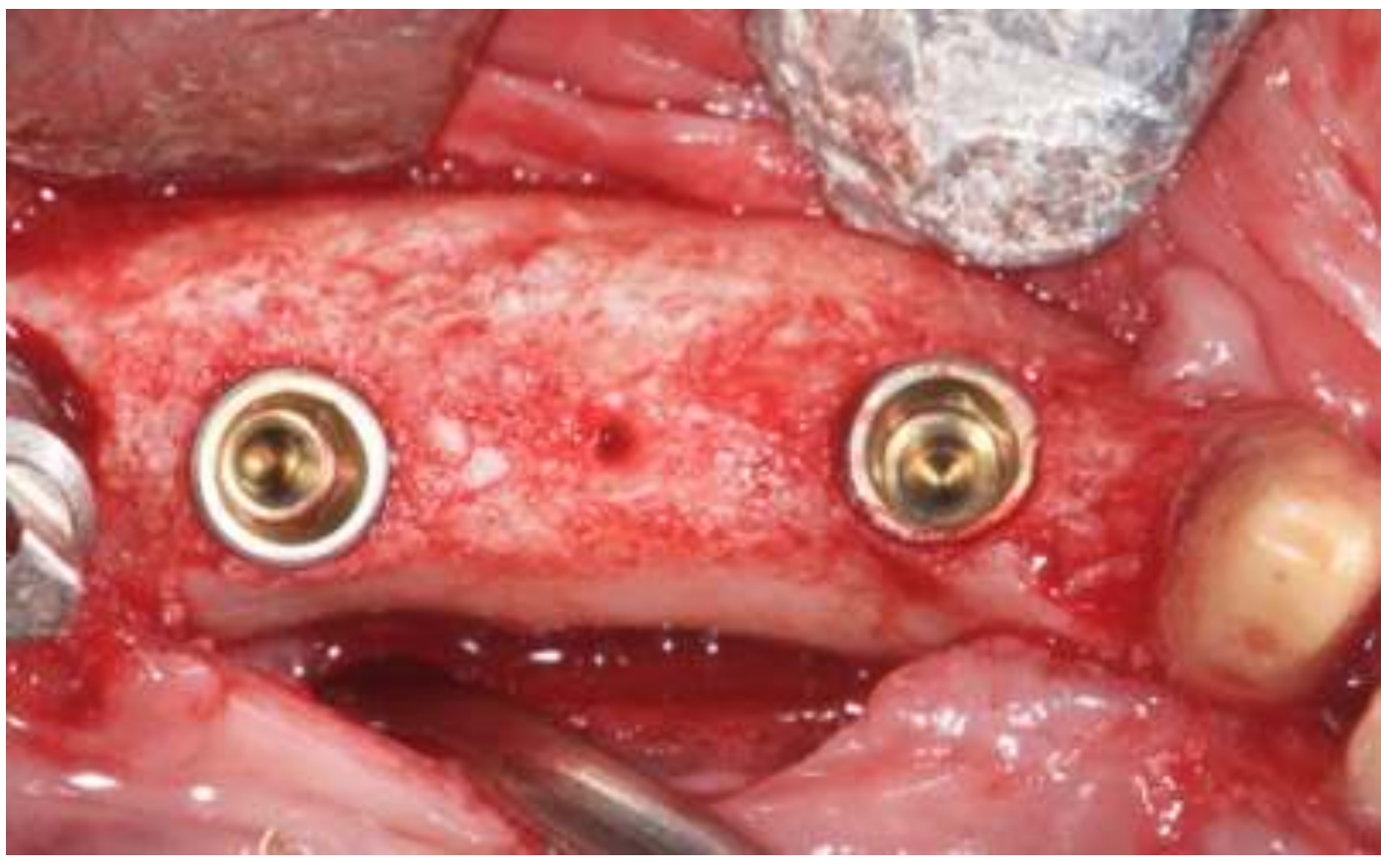

Soft tissue healing after gengiva-graft

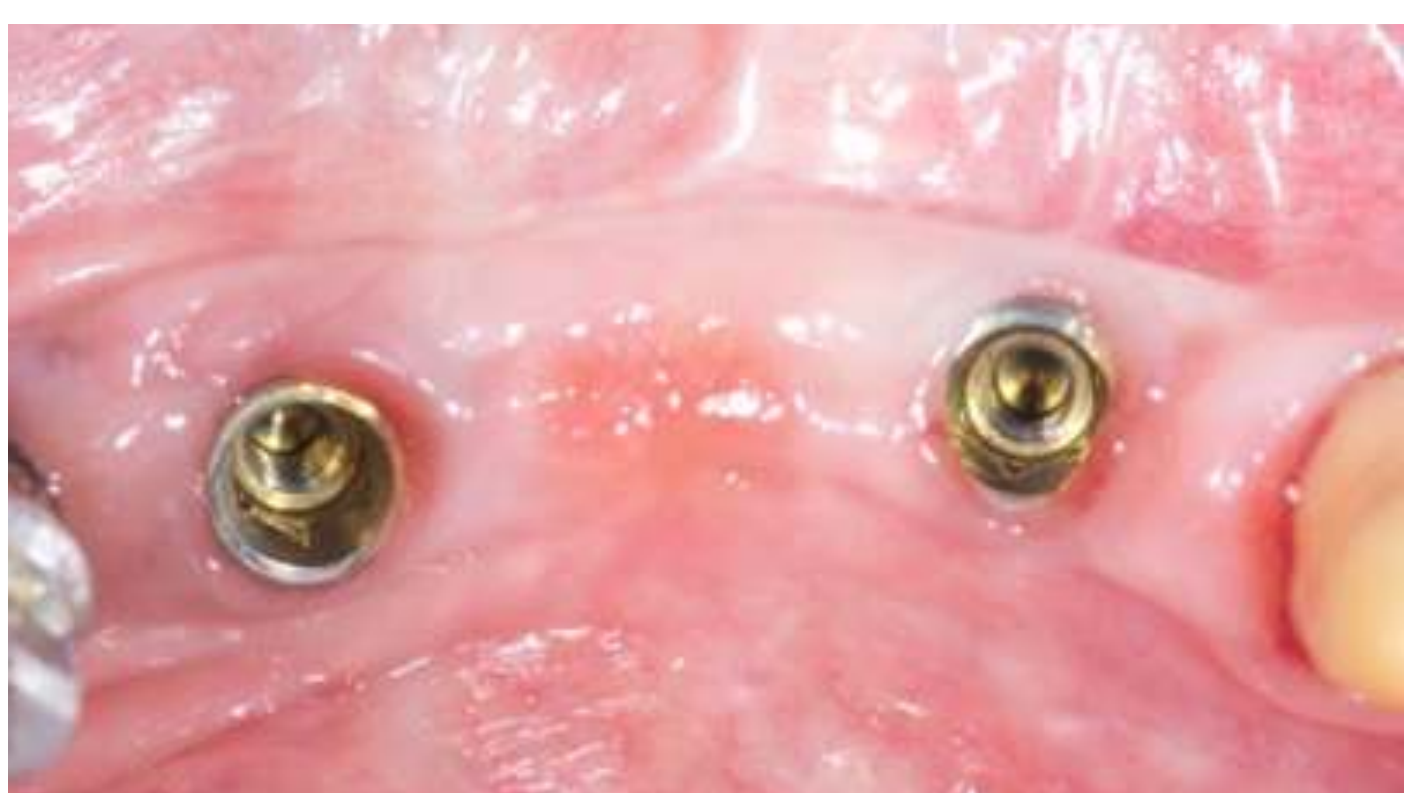

Final prosthesis 3 year follow-up 